\title{
Impulse Control Disorders and Dopamine-Related Creativity: Pathogenesis and Mechanism, Short Review, and Hypothesis
}

\author{
Pedro J. Garcia-Ruiz*
}

Movement Disorders Unit, Department of Neurology, Hospital Universitario Fundación Jiménez Díaz, Madrid, Spain

Impulse control disorder (ICD), including pathological gambling, hypersexuality, and compulsive shopping has been linked to antiparkinsonian medication, especially dopamine agonists. The mechanism of ICD is not completely clear, but it seems that ICD is the result of an activation of dopamine receptors, mostly D3 in the ventral striatum. Patients treated with dopamine agonists that have preferential affinity for D3 (including ropinirole and pramipexole) are much more prone to develop ICD. In addition, a genetic component is probably present, especially in young patients. Finally, environment and lifestyle may also play a role: those patients engaged in physical, social, and artistic

OPEN ACCESS

Edited by:

Mayela Rodríguez-Violante, Instituto Nacional de Neurología y

Neurocirugía (INNN), Mexico

Reviewed by:

Alvaro Sanchez-Ferro, Centro Integral en Neurociencias A.C. HM CINAC, Spain

Sara Palermo,

Università degli Studi di Torino, Italy

*Correspondence:

Pedro J. Garcia-Ruiz pgarcia@fjd.es

Specialty section: This article was submitted to

Movement Disorders, a section of the journal

Frontiers in Neurology

Received: 22 August 2018 Accepted: 19 November 2018 Published: 06 December 2018

Citation:

Garcia-Ruiz PJ (2018) Impulse Control

Disorders and Dopamine-Related

Creativity: Pathogenesis and

Mechanism, Short Review, and

Hypothesis. Front. Neurol. 9:1041.

doi: 10.3389/fneur.2018.01041 activities are probably less likely to develop ICD compared to those patients with poor physical activity living in isolated environments.

Keywords: impulse control disorder, dopamine agonists, genetics, environment, enhanced creativity

\section{INTRODUCTION}

Impulse control disorder (ICD) is currently one of the most frequent and devastating side effects of antiparkinsonian medication. J.A. Molina was the first author to describe gambling as a peculiar and typical manifestation of ICD (1). He found several gamblers among his patients by chance (1); over time, it became clear that ICD was very frequent in Parkinson disease (PD), that this disorder was very complex (2-5); and included several abnormal behaviors such as gambling, hypersexuality, compulsive shopping, kleptomania, and eating disorders $(4,5)$. It was also clear that ICD was associated with antiparkinsonian drugs, mainly dopamine agonists $(6,7)$. The relationship of dopamine agonists and ICD has been confirmed in several studies (6-10), most especially in young individuals (11). This review discusses several aspects concerning the pathogenesis and mechanisms of this common and devastating condition.

\section{IMPULSE CONTROL DISORDER AS A DOPAMINERGIC SIDE EFFECT}

The mechanisms of ICD are not completely clear, but several clues have emerged over time. PD itself does not seem to confer an increased risk for development of ICD (12), thus making ICD mainly a drug-related side effect.

Dopaminergic medication - primarily dopamine agonists (4-11), occasionally MAO-inhibitors $(7,13)$, and, only rarely, levodopa (14) - has been associated with ICD. Dopamine agonists are clearly related to ICD, not only in PD, but also in restless legs syndrome $(10,15)$, and occasionally hyperprolactinemia $(10,16)$. 
Although its mechanism is still partially unknown, Castrioto et al. (17) suggested an interesting framework to explain ICD in opposition to apathy in PD. Apathy and ICD (like akinesia and dyskinesia) lie at the opposite ends of a spectrum of dopaminergic tone. Pulsatile dopaminergic medication induces sensitization of the limbic ventral striatum and the motor dorsal striatum. This sensitization may lead to a shift from apathy to ICD (and, from a motor point of view, from bradykinesia to dyskinesia). In this regard, Jimenez-Urbieta et al. suggested that levodopa-related dyskinesias and ICD could be defined as a maladaptation to dopaminergic therapy (18). These elegant and plausible hypotheses certainly explain ICD in the context of PD, but they do not explain the occurrence of ICD in other nonparkinsonian conditions such as restless legs syndrome, in which no dopaminergic neurodegeneration is present. In any case, the contribution of the dopaminergic system to the pathophysiology of ICD is solid $(17,18)$. In addition, Palermo et al. (19) suggested an interesting neurocognitive approach to ICD; these authors suggest that a fronto-striatal and cingulo-frontal dysfunction may reflect impairment in metacognitive-executive abilities (such as response-inhibition, action monitoring, and error awareness) and promote compulsive repetition of behavior. In this regard ICD could be partly defined as a response-inhibition disability (19).

Dopamine agonists are by far the most frequent drugs associated with ICD (4-11), but there is still an ongoing debate; for some authors, ICD could be defined as a dopamine agonist class effect, with all dopamine agonists sharing this side effect (7). Recently, however, several studies have suggested that some dopamine agonists (including ropinirole and pramipexole) are much more strongly associated with $\operatorname{ICD}$ than rotigotine $(9,10)$ or apomorphine (10). Although the figures vary, in general terms the relative risk of ICD is as follows: pramipexole $>$ ropinirole $>$ rotigotine $>$ apomorphine $(9,10,20)$. The reason for this difference is unknown, but according to Seeman (20) those dopamine agonists with preferential affinity for the D3 receptor are much more likely to be associated with ICD compared to other less selective agonists, and in general terms, the relative risk of ICD is proportional to D3 affinity (20). And even so, rotigotine and apomorphine are also associated with $\operatorname{ICD}(9,10)$; in fact, the most severe case of ICD we have ever seen was related to apomorphine, and it seems that there is no dopamine agonist that is entirely free from ICD. Treatment of ICD is a challenge. Reduction and/or suppression of dopamine agonists is usually recommended (18), but ICD is not easily reversible. The substitution of a high affinity dopamine D3 agonist for another less selective dopamine agonists is not always successful. Levy and Lang suggested that previous remote exposure to a dopamine agonist may prime patients to develop ICD with further dopaminergic medication (13). In this regard, dopamine agonists may predispose the striatum to develop ICD and medication-related dyskinesias as well $(13,17,18)$. Besides the reduction/withdrawal of dopamine agonists, a plethora of therapeutic measures has been suggested, including atypical neuroleptics such as clozapine and quetiapine $(21,22)$, anticonvulsants (23), amantadine (24), selective serotonin reuptake inhibitors, and opioid antagonists (25) to mention just a few. There is no solid evidence for the effectiveness of these drugs (25). Recently it has been suggested that intraduodenal infusion of levodopa-carbidopa might help (26), though this measure is probably valid in the presence of an important reduction of dopamine agonist, and in any case, there are also anecdotal reports of ICD after the introduction of levodopa-carbidopa infusion (14). Some other authors suggest that deep brain stimulation (DBS) might be useful for patients with ICD (27); similarly, however, this measure is probably effective only if an important reduction of dopamine agonist is carried out $(25,28)$. It is important to keep in mind that there are reports of cases of ICD occurring after DBS $(25,28)$. We have had experience with some parkinsonian patients with ICD submitted for DBS; surgical intervention did not improve their ICD despite a profound reduction of dopamine medication and excellent motor control.

\section{GENETIC ASPECTS OF IMPULSE CONTROL DISORDERS}

Since not all individuals with PD taking dopamine agonists develop ICD, a genetic component is also likely. In addition,

TABLE 1 | Creativity related to dopaminergic drugs.

\begin{tabular}{lllllll}
\hline Subject & Age/Sex & Years & Motor Compl. & LD & Dopamine agonist & Artistic activity \\
\hline 1 & $69 / M$ & 10 & F,GF,D & $+(+R)$ & ROP & Painting, scale models, woodwork \\
2 & $70 / M$ & 8 & GF & $+(+R)$ & PRM & SCALE models (SHIPS) \\
3 & $74 / M$ & 10 & F,GF & + & PRM & Gardening \\
4 & $75 / M$ & 8 & F & $+(+R)$ & PRM & Painting \\
5 & $67 / F$ & 5 & - & $+(+R)$ & PRM & Painting/dance/theater \\
6 & $53 / F$ & 5 & D & $+(+E)$ & - & Painting \\
7 & $71 / M$ & 12 & - & $+(+R)$ & ROT & Gardening \\
8 & $80 / M$ & 12 & F & + & PRM & Carving, engraving \\
9 & $60 / M$ & 8 & F,GF & $+(+R)$ & PRM & Scale models (TRAIN) \\
10 & $80 / F$ & & $+(+R)$ & PRM & Painting (>100)
\end{tabular}

Motor Comp., Complications; F, Fluctuations; GF, Gait freezing; D, Dyskinesias; LD, Levodopa; ROP, Ropinirole; PRA, Pramipexole; ROT, Rotigotine; R, Rasagiline; E, Entecapone. 
there are similarities between the phenotypic presentation of ICD and that of other reward-based behavioral disorders, including binge-eating disorder, pathological gambling, and substance-use disorder $(19,29)$.

In the general population, genetic factors might contribute up to $60 \%$ of the variance in the risk for substanceuse disorders and pathological gambling (30); hence, a genetic component of ICD has been pursued as a viable explanation.

First, although newly diagnosed but still untreated patients with PD do not have an increased risk of developing an ICD when compared to controls (12), certain subpopulations such as younger patients (11) and Parkin mutation carriers (31) do have increased risk.

To date, several polymorphisms of dopaminergic genes have been associated with ICD in PD patients (32-36). However, some findings have challenged this relation, probably due to differences in study design, method of ICD behavior assessment, cohort characteristics, and ethnic background (32-36). The most promising candidate at present is probably the DRD3 single nucleotide variation (SNV) rs6280 (35, 36), which has been associated with ICD in early onset PD in European and Asian patients $(35,36)$.

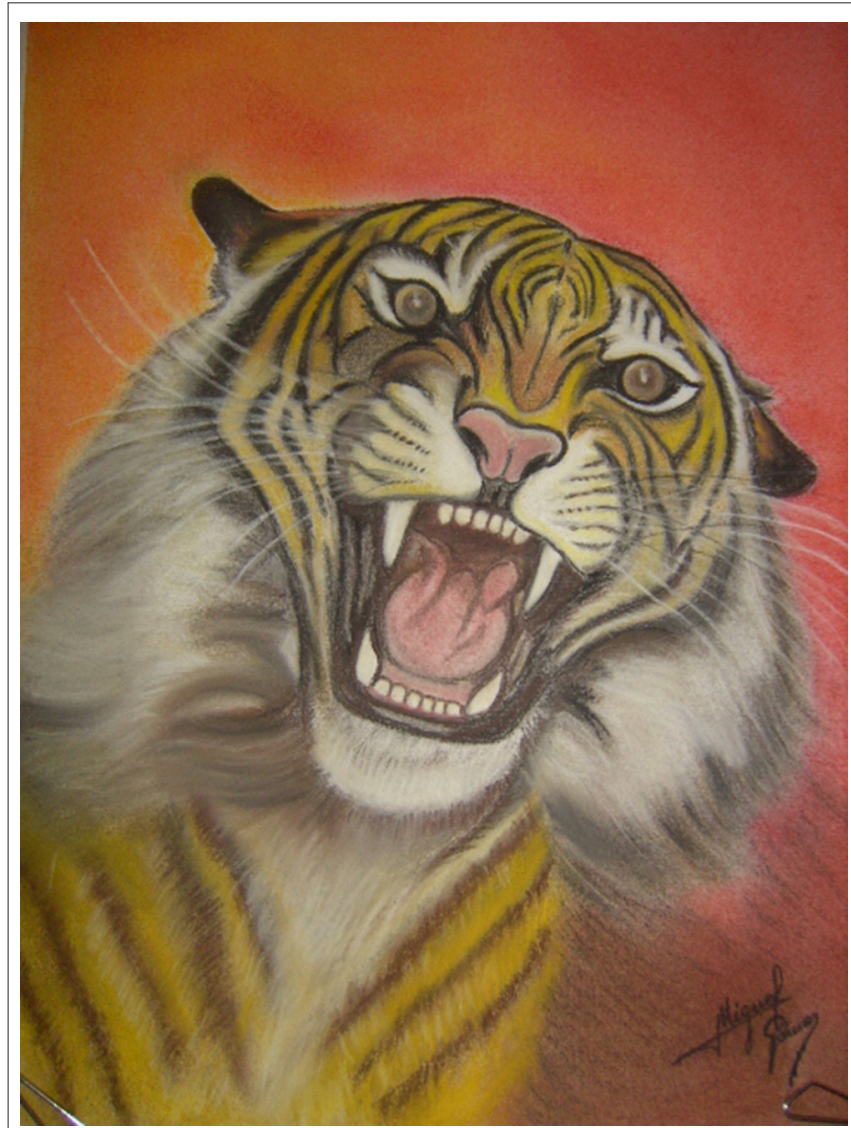

FIGURE 1 | This patient combines realistic portraits and modeling.
In any case, it is evident that multiple factors influence the presence of ICD. Several recent papers found that ICD was mainly associated with an early onset of the disease, dopamine agonist treatment, and the presence of the rs6280 DRD3 SNV $(35,36)$
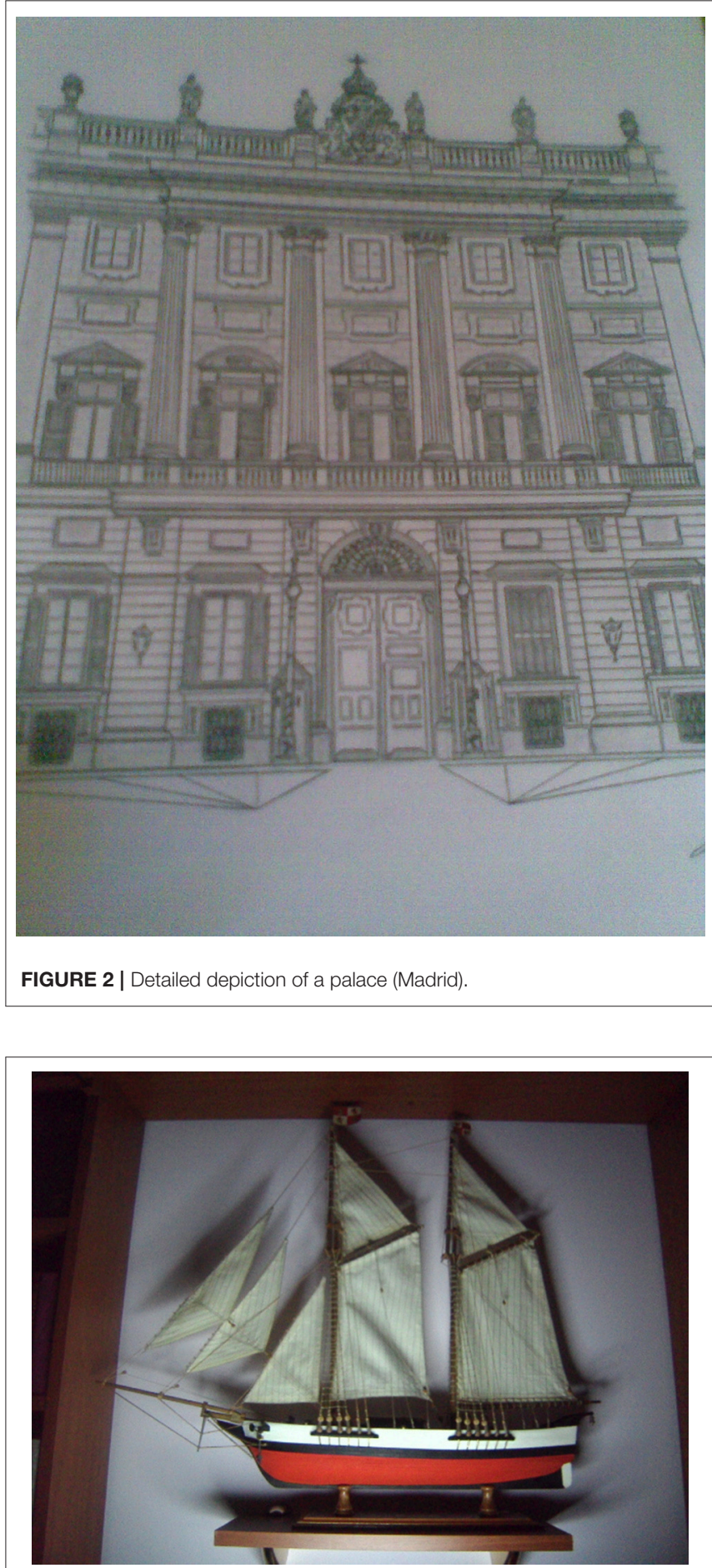

FIGURE 3 | Ship modeling (Schooner), another classic from our patients. 


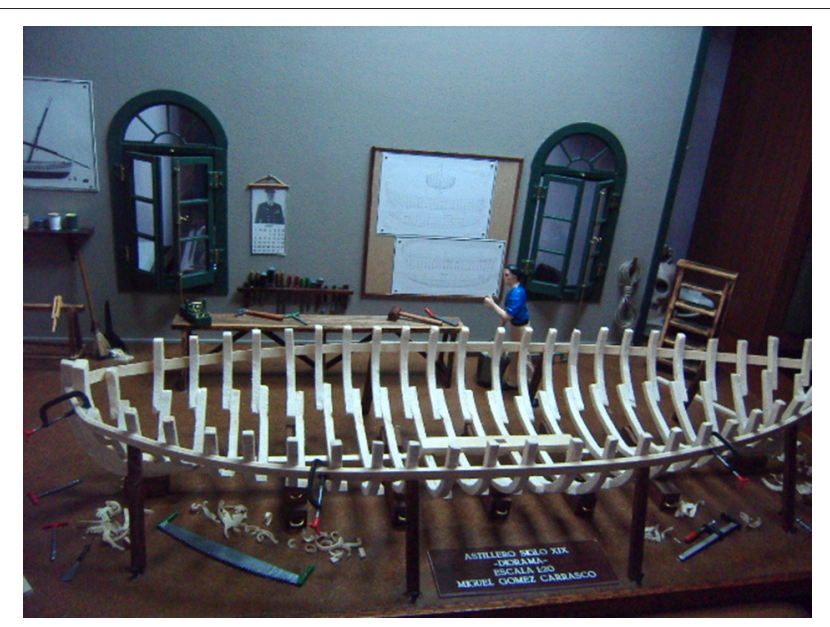

FIGURE 4 | Highly detailed boatyard model.

TABLE 2 | Impulse control disorders and dopaminergic creativity short review and hypothesis.

- Impulse control disorder (ICD) has been linked to antiparkinsonian medication especially dopamine agonists

- The mechanism of ICD is not completely clear, but activation of dopamine D3 receptor is likely; those patients treated with dopamine agonists with higher affinity to D3 (including ropinirole and pramipexole) are much more prone to develop ICD

- A genetic component is probably present, especially in young patients

- The management of ICD includes reduction/suppression of dopamine agonists

- Occasionally, dopamine agonists enhance creativity and the patients engage in artistic, non-disruptive behavior described as positive by patients and families

- Probably, the environment influences the apparition of enhanced creativity, our hypothesis is that fostering a rich and stimulating environment for patients with PD may contribute to the appearance of the enhanced creativity phenomenon instead of ICD.

\section{IMPULSE CONTROL DISORDERS, ENHANCED CREATIVITY, AND ENVIRONMENT}

Epidemiological studies revealed that ICD figures vary depending on the country as well as social and economic factors $(7-9,11$, 37). Even the characteristics of ICD vary depending on the study (hypersexuality, gambling, compulsive eating, etc., depending on the country) $(7-11,37)$, hence several environmental factors clearly play a role in the development of the disorder $(7,9,11,37)$.

Another related and interesting aspect is that occasionally, dopamine agonists give rise to enhanced creativity in $\mathrm{PD}$ patients, many without previous artistic abilities (38-43); this non-disruptive behavior is described as positive by patients and families. Canesi et al. suggested that artistic-like production might represent the emerging of innate skills in a subset of predisposed patients with PD on dopaminergic therapy (39).

At our center, we have had the chance to follow 10 PD patients with this "newfound talent" and the impact on their lives has been positive, in contrast with the much more frequent ICD. All these patients began their artistic activity after dopaminergic medication (Table 1), most had motor complications including motor fluctuations (7/10), gait freezing (3/10), or dyskinesias (3/10). All but one patient were treated with dopamine agonists including pramipexole (7/9), ropinirole (1/9), or rotigotine (1/9).

Most patients with this new artistic activity preferred painting as their main medium, but many were engaged in several activities, usually in combination (Figures 1-4 show some of the art produced by these patients). Some patients began their artistic endeavor after meeting with other subjects already engaged in artistic activities (personal observation). Our hypothesis is that fostering a rich and stimulating environment for patients with PD may contribute to the appearance of this dopamine agonistrelated positive phenomenon instead of ICD.

\section{CONCLUSION}

In summary, ICD is a complex antiparkinsonian medicationrelated situation most commonly associated with dopamine agonists. Since not all parkinsonian patients suffer from ICD, a genetic component has been pursued. Young patients, including parkin carriers, have increased risk. In addition, environmental factors may also play a role. In any case, early detection of IDC is of paramount importance, as patients must be warned of the onset of this rather frequent side effect.

Recently, a positive, non-disruptive, dopamine agonist-related effect has been noted. Some parkinsonian patients develop enhanced creativity after being treated with dopamine agonists. Facilitating a positive environment (including artistic and cultural activities) for parkinsonian patients may contribute to enhanced creativity instead of ICD. Table 2 summarizes the most relevant points of ICD.

\section{AUTHOR CONTRIBUTIONS}

PG-R: conception and design, interpretation of data, drafting the submitted material, and critical review.

\section{ACKNOWLEDGMENTS}

Art examples from some patients were presented at the 20th Congress on Parkinson's disease and Movement Disorders. Berlin. June 19-23, 2016. The local ethics committee approved this work and the patients consented to have their artwork appear as part of this study. We appreciate the editorial assistance of Dr. Oliver Shaw. 


\section{REFERENCES}

1. Molina JA, Sáinz-Artiga MJ, Fraile A, Jiménez-Jiménez FJ, Villanueva C, Ortí-Pareja M, et al. Pathologic gambling in Parkinson's disease: a behavioral manifestation of pharmacologic treatment? Mov Disord. (2000) 15:869-72. doi: 10.1002/1531-8257(200009)15:5<869::AID-MDS1016>3.0.CO;2-I

2. Weintraub D, Hoops S, Shea JA, Lyons KE, Pahwa R, Driver-Dunckley ED, et al. Validation of the questionnaire for impulsive-compulsive disorders in Parkinson's disease. Mov Disord. (2009) 24:1461-7. doi: 10.1002/mds.22571

3. Weintraub D, Koester J, Potenza MN, Siderowf AD, Stacy M, Voon V, et al. Impulse control disorders in Parkinson disease: a cross-sectional study of 3090 patients. Arch Neurol. (2010) 67:589-95. doi: 10.1001/archneurol.2010.65

4. Voon V, Mehta AR, Hallett M. Impulse control disorders in Parkinson's disease: recent advances. Curr Opin Neurol. (2010) 24:324-30. doi: 10.1097/WCO.0b013e3283489687

5. Weintraub D, David AS, Evans AH, Grant JE, Stacy M. Clinical spectrum of impulse control disorders in Parkinson's disease. Mov Disord. (2015) 30:121-7. doi: $10.1002 / \mathrm{mds} .26016$

6. Weintraub D, Siderowf AD, Potenza MN, Goveas J, Morales $\mathrm{KH}$, Duda JE, et al. Association of dopamine agonist use with impulse control disorders in Parkinson disease. Arch Neurol. (2006) 63:969-73. doi: 10.1001/archneur.63.7.969

7. Perez-Lloret S, Rey MV, Fabre N, Ory F, Spampinato U, Brefel-Courbon C, et al. Prevalence and pharmacological factors associated with impulse-control disorder symptoms in patients with Parkinson disease. Clin Neuropharmacol. (2012) 35:261-5. doi: 10.1097/WNF.0b013e31826e6e6d

8. Bastiaens J, Dorfman BJ, Christos PJ, Nirenberg MJ. Prospective cohort study of impulse control disorders in Parkinson's disease. Mov Disord. (2013) 28:327-33. doi: 10.1002/mds.25291

9. Garcia-Ruiz PJ, Martinez Castrillo JC, Alonso-Canovas A, Herranz Barcenas A, Vela L, Sanchez Alonso P, et al. Impulse control disorder in patients with Parkinson's disease under dopamine agonist therapy: a multicentre study. $J$ Neurol Neurosurg Psychiatry (2014) 85:840-4. doi: 10.1136/jnnp-2013-306787

10. Moore TJ, Glenmullen J, Mattison DR. Reports of pathological gambling, hypersexuality, and compulsive shopping associated with dopamine receptor agonist drugs. JAMA Intern Med. (2014) 174:1930-3. doi: 10.1001/jamainternmed.2014.5262

11. Vela L, Martínez Castrillo JC, García Ruiz P, Gasca-Salas C, Macías Macías Y, Pérez Fernández E, et al. The high prevalence of impulse control behaviors in patients with early-onset Parkinson's disease: a cross-sectional multicenter study. J Neurol Sci. (2016) 368:150-4. doi: 10.1016/j.jns.2016.07.003

12. Weintraub D, Papay K, Siderowf A. Parkinson's Progression Markers Initiative. Screening for impulse control symptoms in patients with de novo Parkinson disease: a case-control study. Neurology (2013) 80:176-80. doi: 10.1212/WNL.0b013e31827b915c

13. Levy A, Lang AE. Recurrent impulse control disorder associated with rasagiline treatment of Parkinson's disease. Can J Neurol Sci. (2017) 44: 447-8. doi: $10.1017 / \operatorname{cjn} .2016 .307$

14. Ricciardi L, Espay KJ, Krikorian R, Fasano A, Espay AJ. Dopamine dysregulation syndrome with psychosis in 24-hour intestinal levodopa infusion for Parkinson's disease. Parkinsonism Relat Disord. (2016) 28:152-4. doi: 10.1016/j.parkreldis.2016.03.014

15. Marques A, Figorilli M, Pereira B, Derost P, Debilly B, Beudin P, et al. Impulse control disorders in Parkinson's disease patients with RLS: a cross sectional-study. Sleep Med. (2018) 48:148-54. doi: 10.1016/j.sleep.2018.02.004

16. Martinkova J, Trejbalova L, Sasikova M, Benetin J, Valkovic P. Impulse control disorders associated with dopaminergic medication in patients with pituitary adenomas. Clin Neuropharmacol. (2011) 34:179-81. doi: 10.1097/WNF.0b013e3182281b2f

17. Castrioto A, Thobois S, Carnicella S, Maillet A, Krack P. Emotional manifestations of PD: neurobiological basis. Mov Disord. (2016) 31:1103-13. doi: $10.1002 / \mathrm{mds} .26587$

18. Jiménez-Urbieta $H$, Gago $B$, de la Riva $P$, Delgado-Alvarado $M$, Marin C, Rodriguez-Oroz MC. Dyskinesias and impulse control disorders in Parkinson's disease: from pathogenesis to potential therapeutic approaches. Neurosci Biobehav Rev. (2015) 56:294-314. doi: 10.1016/j.neubiorev.2015.07.010
19. Jiménez-Urbieta H, Gago B, de la Riva P, Delgado-Alvarado M, Marin C, Rodriguez-Oroz MC. Impulse control disorder and response-inhibition alterations in Parkinson's disease. A rare case of totally absent functionality of the medial-prefrontal cortex and review of literature. J Adv Res. (2017) 8:713-6. doi: 10.1016/j.jare.2017.09.004

20. Seeman P. Parkinson's disease treatment may cause impulse-control disorder via dopamine D3 receptors. Synapse (2015) 69:183-9. doi: 10.1002/syn.21805

21. Rotondo A, Bosco D, Plastino M, Consoli A, Bosco F. Clozapine for medication-related pathological gambling in Parkinson disease. Mov Disord. (2010) 25:1994-5. doi: 10.1002/mds.23177

22. Sevincok L, Akoglu A, Akyol A. Quetiapine in a case with Parkinson disease and pathological gambling. J Clin Psychopharmacol. (2007) 27:107-8. doi: 10.1097/JCP.0b013e31802e98c3

23. Hicks CW, Pandya MM, Itin I, Fernandez HH. Valproate for the treatment of medication-induced impulse-control disorders in three patients with Parkinson's disease. Parkinson Relat Disord. (2011) 17:379-81. doi: 10.1016/j.parkreldis.2011.03.003

24. Cera N, Bifolchetti S, Martinotti G, Gambi F, Sepede G, Onofrj M., et al. Amantadine and cognitive flexibility: decision making in Parkinson's patients with severe pathological gambling and other impulse control disorders. Neuropsychiatr Dis Treat. (2014) 10:1093-101. doi: 10.2147/NDT.S54423

25. Zhang S, Dissanayaka NN, Dawson A, O'Sullivan JD, Mosley P, Hall W., et al. Management of impulse control disorders in Parkinson's disease. Int Psychogeriatr. (2016) 28:1597-614. doi: 10.1017/S104161021600096X

26. Catalan MJ, Molina-Arjona JA, Mir P, Cubo E, Arbelo JM, Martinez-Martin P., et al. EDIS Study Group. Improvement of impulse control disorders associated with levodopa-carbidopa intestinal gel treatment in advanced Parkinson's disease. J Neurol. (2018) 265:1279-87. doi: 10.1007/s00415-018-8803-1

27. Merola A, Romagnolo A, Rizzi L, Rizzone MG, Zibetti M, Lanotte M., et al. Impulse control behaviors and subthalamic deep brain stimulation in Parkinson disease. J Neurol. (2017) 264:40-8. doi: 10.1007/s00415-016-8314-x

28. Kasemsuk C, Oyama G, Hattori N. Management of impulse control disorders with deep brain stimulation: a double-edged sword. J Neurol Sci. (2017) 374:63-8. doi: 10.1016/j.jns.2017.01.019

29. Lopez AM, Weintraub D, Claassen DO. Impulse control disorders and related complications of Parkinson's disease therapy. Semin Neurol. (2017) 37:186-92. doi: 10.1055/s-0037-1601887

30. Eisen SA, Lin N, Lyons MJ, Scherrer JF, Griffith K, True WR., et al. Familial influences on gambling behavior: an analysis of 3359 twin pairs. Addiction (1998) 93:1375-84. doi: 10.1046/j.1360-0443.1998.93913758.x

31. Morgante F, Fasano A, Ginevrino M, Petrucci S, Ricciardi L, Bove F., et al. Impulsive-compulsive behaviors in Parkin-associated Parkinson disease. Neurology (2016) 87:1436-41. doi: 10.1212/WNL.0000000000003177

32. Vallelunga A, Flaibani R, Formento-Dojot P, Biundo R, Facchini S, Antonini A. Role of genetic polymorphisms of the dopaminergic system in Parkinson's disease patients with impulse control disorders. Parkinson Relat Disord. (2012) 18:397-9. doi: 10.1016/j.parkreldis.2011.10.019

33. Ziegler DA, Ashourian P, Wonderlick JS, Sarokhan AK, Prelec D, Scherzer CR., et al. Motor impulsivity in Parkinson disease: associations with COMT and DRD2 polymorphisms. Scand J Psychol. (2014) 55:278-86. doi: $10.1111 /$ sjop.12113

34. Hoenicka J, García-Ruiz PJ, Ponce G, Herranz A, Martínez-Rubio D, PérezSantamarina E., et al. The addiction-related gene ANKK1 in Parkinsonian patients with impulse control disorder. Neurotox Res. (2015) 27:205-8. doi: 10.1007/s12640-014-9504-x

35. Krishnamoorthy S, Rajan R, Banerjee M, Kumar H, Sarma G, Krishnan $\mathrm{S}$, et al. Dopamine D3 receptor Ser9Gly variant is associated with impulse control disorders in Parkinson's disease patients. Parkinson Relat Disord. (2016) 30:13-7. doi: 10.1016/j.parkreldis.2016.06.005

36. Castro-Martínez XH, García-Ruiz PJ, Martínez-García C, Martínez-Castrillo JC, Vela L, Mata M, et al. Behavioral addictions in early-onset Parkinson disease are associated with DRD3 variants. Parkinson Relat Disord. (2018) 49:100-3. doi: 10.1016/j.parkreldis.2018.01.010

37. Rodríguez-Violante M, González-Latapi P, Cervantes-Arriaga A, CamachoOrdoñez A, Weintraub D. Impulse control and related disorders in Mexican Parkinson's disease patients. Parkinson Relat Disord. (2014) 20:907-10. doi: 10.1016/j.parkreldis.2014.05.014 
38. Kulisevsky J, Pagonabarraga J, Martinez-Corral M. Changes in artistic style and behaviour in Parkinson's disease: dopamine and creativity. J Neurol. (2009) 256:816-9. doi: 10.1007/s00415-009-5001-1

39. Canesi M, Rusconi ML, Isaias IU, Pezzoli G. Artistic productivity and creative thinking in Parkinson's disease. Eur J Neurol. (2012) 19:468-72. doi: 10.1111/j.1468-1331.2011.03546.x

40. Inzelberg R. The awakening of artistic creativity and Parkinson's disease. Behav Neurosci. (2013) 127:256-61. doi: 10.1037/a00 31052

41. Lhommée E, Batir A, Quesada JL, Ardouin C, Fraix V, Seigneuret E, et al. Dopamine and the biology of creativity: lessons from Parkinson's disease. Front Neurol. (2014) 5:55. doi: 10.3389/fneur.2014.00055

42. Faust-Socher A, Kenett YN, Cohen OS, Hassin-Baer S, Inzelberg R. Enhanced creative thinking under dopaminergic therapy in Parkinson disease. Ann Neurol. (2014) 75:935-42. doi: 10.1002/ana.24181
43. Canesi M, Rusconi ML, Moroni F, Ranghetti A, Cereda E, Pezzoli G. Creative thinking, professional artists, and Parkinson's disease. J Parkinsons Dis. (2016) 6:239-46. doi: 10.3233/JPD-150681

Conflict of Interest Statement: PG-R received research support from Allergan and UCB, personal compensation as a consultant/scientific advisory board from Italfarmaco, Britannia, Bial, and Zambon and speaking honoraria from Italfarmaco, UCB, Zambon, Allergan, and Abbvie.

Copyright (C) 2018 Garcia-Ruiz. This is an open-access article distributed under the terms of the Creative Commons Attribution License (CC BY). The use, distribution or reproduction in other forums is permitted, provided the original author(s) and the copyright owner(s) are credited and that the original publication in this journal is cited, in accordance with accepted academic practice. No use, distribution or reproduction is permitted which does not comply with these terms. 